\title{
Genetic diversity assessment of Tunisian Mycobacterium bovis population isolated from cattle
}

\author{
Saif Eddine Djemal ${ }^{1 *}$ (D), Mariam Siala ${ }^{1,2}$, Salma Smaoui ${ }^{3,4,5}$, Sana Kammoun ${ }^{3,4,5}$, Chema Marouane ${ }^{3,4,5}$,
} Javier Bezos ${ }^{6,7}$, Feriele Messadi-Akrout ${ }^{3,4,5}$, Beatriz Romero ${ }^{7}$ and Radhouane Gdoura ${ }^{1}$

\begin{abstract}
Background: The genetic diversity of M. bovis in Tunisia is still underestimated despite the implementation of an eradication program. The lack of data about spatial distribution of the M. bovis population hinders the control of bovine tuberculosis (bTB) progress. This study represents the largest molecular analysis of M. bovis isolates in Tunisia. It is aimed to upgrade the understanding of bTB epidemiology and the geographical distribution of the infection. Tuberculosis research was performed in cattle $(n=149)$ with TB-compatible lesions collected over 5 months from a slaughterhouse located in Sfax, Tunisia.

Results: Ninety-four animals were found to be infected by M. bovis and two others by M. caprae. Spoligotyping revealed twenty-five patterns, SB0120, SB0134, and SB0121 being the most prevalent profiles (36.4\%, 11.4\%, and 7.2\%, respectively). Three new spoligotypes were detected: SB2345, SB2344 and SB2343. MIRU-VNTR analysis classified the isolates in seventy-three profiles and showed a large genotypic variety observed within the main spoligotype which was split into several MIRU-VNTR types: 29 in SB0120 $(h=0.983), 10$ in SB0134 $(h=0.981)$ and 7 in SB0121 $(h=1)$. Genotyping revealed a common pattern in different geographic regions. It also showed that Sfax, located in southern-Tunisia, represents a high-risk area with an elevated genetic diversity.
\end{abstract}

Conclusions: Spatial analysis may provide insights into disease transmission, which affects the effectiveness of eradication campaigns in cattle.

Keywords: Mycobacterium Bovis, Genetic diversity, Spoligotyping, MIRU-VNTR typing

\section{Background}

Bovine tuberculosis (bTB) is one of the seven endemic zoonoses neglected worldwide, especially in developing countries [1]. It is mainly caused by $M$. bovis, a member of the Mycobacterium tuberculosis complex (MTBC). M. bovis has a wide host range and can affect various target species, including domesticanimals, mainly cattle. $M$. bovis can be transmitted from animals to humans in close contact including aerosols, consuming unpasteurized milk or dairy products and less often by skin contact.

\footnotetext{
* Correspondence: saifjemal@hotmail.fr

${ }^{1}$ Department of Life Sciences, Research Laboratory of Environmental Toxicology-Microbiology and Health (LR17ES06), Faculty of Sciences, University of Sfax-Tunisia, Sfax, Tunisia

Full list of author information is available at the end of the article
}

A national bTB control program has been implemented in Tunisia since 1984 based essentially on the intra-dermal tuberculin skin testing and routine slaughterhouse meat inspections of dairy cattle [2].

In fact, there are two livestock sectors characterized as follows:

- The organized intensive livestock belonging to the state and subjected to the BTB eradication program.

- The private sector is the so-called unorganized Tunisian livestock, which consists of 60 to $70 \%$ of the whole bovine livestock and extensive or semiextensive cattle herds belonging to private owners [3]. Nevertheless, the bTB is still prevalent mainly in the private sector where disease control is based on a scarce veterinary activity limited to visual 
inspection of carcasses in slaughterhouses without routine intra-dermal tuberculin skin testing. From January to August 2013, 499 cows showed TBcompatible lesions during the meat inspection among 37,060 slaughtered animals [4]. Moreover, the majority of Tunisian cattle are not registered and cattle movement control schemes are unknown. Most of the bTB cases in Tunisia are discovered during meat inspection of cattle slaughtered at regular slaughterhouses when gross visible lesions typical of the disease are detected. However, in two recent Tunisian studies, $M$. bovis was isolated from milk and in $35 \%$ of the cattle exhibiting lesions $[3,5]$. This suggests that bTB caused by $M$. bovis still persists in animals and thus could affect ecosystems and cause human extra-pulmonary tuberculosis (EPTB). In fact, in Tunisia, the prevalence of $M$. bovis as a causative agent of EPTB is high and divergent from studies in African countries [6]. Recently, Ghariani et al. and Siala et al. have shown that $M$. bovis, the agent of bovine $\mathrm{TB}$, is a major cause of lymphadenitis TB with a frequency of $57 \%$ in north and $76 \%$ in south Tunisia, respectively $[7,8]$. Consumption of not well-cooked meat and drinking raw milk from infected animals are common practices and could be the main causes of human EPTB [7, 8].

Spacer oligonucleotide typing (spoligotyping) and Variable Number of Tandem Repeat (VNTR) typing have been shown to be efficient tools to discriminate between M. bovis isolates $[9,10]$.

The ability to compare $M$. bovis isolates in the same country and among countries could help understand the distribution of $M$. bovis strains. In Tunisia, a large-scale study has not yet been possible since the two existing studies have analysed a low size of samples. In addition, based on the strong historical commercial links between Tunisia and France (the main cattle supplier of Tunisia), a thorough description of the genetic discrimination power of VNTR on French strains of the same spoligotyping group previously published by Hauer et al. [11] could clarify whether the French input to the Tunisian M. bovis population could exist?

Therefore, the main goal of the present work was to study the genetic diversity of a large $M$. bovis population using spoligotyping and VNTR typing and to identify a potential exchange of strains between Tunisia and France.

\section{Methods}

\section{Samples}

Lung, liver, and lymph nodes (retropharyngeal/mandibular, mediastinal/bronchial, portal and mesenteric) were collected from 149 dairy cattle (Frisonne-Holstein breed) with TB-compatible lesions during the veterinary inspection of carcasses. The samples were only taken from the private unorganized livestock sector slaughtered in the largest slaughterhouse in the south of Tunisia from November 2014 to April 2015. Animals belonged to ten geographic regions of Tunisia: Sfax $(n=63)$, Ariana $(n=1)$, Gabes $(n=3)$, Mahdia $(n=13)$, Sidi bouzid $(n=6)$, Kairouan $(n=1)$, Beja $(n=1)$, Jendouba $(n=1)$, Manouba $(n=4)$ and Monastir $(n=3)$. Cattle were 48 male less than 18 month old calves and 101 cull dairy cows aged more than 5 years. Data about municipality and city of origin were obtained from the Ministry of Agriculture according to a registration number given to each cattle.

\section{Bacterial isolation}

Five to ten grams of lymph nodes or lung without fat were cut into small pieces (approx. 50-100 mg) and macerated in $20 \mathrm{~mL}$ sterile distilled water in a Stomacher (BagMixer) until an even suspension was obtained. Tissues from each animal were processed separately. An equal volume of $4 \%$ $(w / v) \mathrm{NaOH}$ was added to the aliquot of tissue suspension to give a final concentration of $2 \%$. After the addition of $\mathrm{NaOH}$, the suspension was vigorously shaken and then incubated at $37{ }^{\circ} \mathrm{C}$ for $30 \mathrm{~min}$, after which time the suspension was neutralized with $10 \% \mathrm{H}_{2} \mathrm{SO}_{4}$. The treated tissue suspensions were centrifuged at $3000 \mathrm{~g}$ for $20 \mathrm{~min}$ and then the supernatant was discarded. Culture media Colestos (Bio-Rad, France) and Lowenstein-Jensen (Bio-Rad, France) were inoculated with the sediment using a cotton swab. The applicator was recharged with sediment before each medium slope was inoculated. The inoculated medium was incubated at $37{ }^{\circ} \mathrm{C}$ for $12-15$ weeks and examined weekly for the presence of colonies [4].

\section{Identification of MTBC by IS6110-PCR}

A loopful of each isolate was harvested into $200 \mathrm{ul}$ TE buffer (10 mM Tris- $\mathrm{HCl}, \mathrm{pH} 8 \pm 0 ; 1 \mathrm{mM}$ EDTA) in screw-cap $1.5 \mathrm{ml}$ microcentrifuge tubes and boiled for $20 \mathrm{~min}$. After centrifugation in $9000 \mathrm{~g}$ for $20 \mathrm{~min}$, the supernatant was transferred to fresh tubes. All DNA extracts were used as template for the identification of MTBC by amplifying the insertion sequence IS6110.

A conventional PCR for the detection of the MTBC was performed to test the DNA samples extracted as well as positive and negative controls, following a previously described protocol [12]. DNA was amplified using 1.25 units of Takara Ex Taq DNA polymerase (Takara Ex taq, Otsu, Shiga, Japan) and $1 \mu$ l of DNA extract. PCR was carried out in a Gene-Amp PCR System 9700 (Applied Biosystems, Foster City, CA, USA). PCR amplification products were visualized using ethidium bromide staining after agarose gel electrophoresis. 


\section{Spoligotyping and MIRU-VNTR typing}

The MTBC strains were spoligotyped as described by Kamerbeek et al. [13] using the spoligotyping membrane made by the VISAVET Health Surveillance Centre (Madrid, Spain). The spoligotyping patterns were assigned according to the Mbovis.org website [14].

MIRU-VNTR analysis was carried out as described by Roring et al. [15] amplifying the loci ETR-A and ETR-B [9], MIRU 4, MIRU 31, MIRU 26 [16, 17], and QUB 3232, QUB 11a, QUB 11b and QUB $26[15,18]$. The amplification program consisted of $15 \mathrm{~min}$ at $95{ }^{\circ} \mathrm{C}$, followed by 40 cycles of $30 \mathrm{~s}$ at $95{ }^{\circ} \mathrm{C}, 60 \mathrm{~s}$ at $60{ }^{\circ} \mathrm{C}$, and $120 \mathrm{~s}$ at $72{ }^{\circ} \mathrm{C}$. Amplicon sizes were estimated by electrophoresis on a $2.5 \%$ agarose gel at $45 \mathrm{~V}$ during $5 \mathrm{~h}$, using 100-bp ladder (Biotools B\&M Labs, Madrid, Spain) and the number of repeats was calculated. The VNTR profiles were named by a $\mathrm{P}$ followed by a correlated number (i.e. P1, P2, P3, etc.).

\section{Data analysis}

A dendogram was built with the unweighted pair group method with arithmetic average (UPGMA) and NJ (Neighbour Joining) clustering methods using the MIRU-VNTR data using Tree graph 2 software. A group of two or more isolates sharing the same MIRU-VNTR pattern was defined as a cluster. The discriminative power of each typing method was calculated using the Hunter-Gaston diversity index (HGDI) [19] using the website application http://insilico.ehu.es/.

\section{Results}

Among the 149 cattle samples with suspicious TB lesions collected between November 2014 and April 2015, live mycobacteria were detected by culture in 99 animals (66.4\%), 96 isolates belonged to $M$. tuberculosis complex and three to atypical mycobacteria. No coinfection with other strains was found in any sample.

Three profiles were typical of $M$. bovis, and two were classified as M. caprae (SB2024 and SB0418 patterns) (Figs. 1 and 2). The discriminatory power of spoligotyping was $h=0.842$.

The most predominant spoligotypes were the SB0120 $(n=35,36.4 \%), \mathrm{SB} 0134(n=11,11.4 \%)$, and SB0121 $(n=7$, $7.2 \%)$. Three new spoligotyping profiles were described (SB2345, SB2344, and SB2343). The geographic distribution of the different spoligotypes is shown in Fig. 1. The region of Sfax showed a very high level of genetic diversity with 20 out of the 25 detected spoligotypes.

The frequency of the three most detected spoligotypes in our strains (SB0120, SB0121, SB0134) was quite similar to those presented in Tunisia by Lamine-Khemiri et al. [3] and are also the three most frequent types observed in France by Hauer et al. [11] (Additional file 1).

All the $96 \mathrm{MTBC}$ isolates were genotyped using nine MIRU-VNTR loci. Seventy-three different VNTR profiles were found (Fig. 2) and two of them were associated to the M. caprae isolates ( $\mathrm{P} 62$ and $\mathrm{P} 68$ ). The discriminatory power for the MIRU-VNTR technique was high $(h=0.992)$. The discriminatory power of the nine individual loci ranged from 0.158 to 0.727 . The
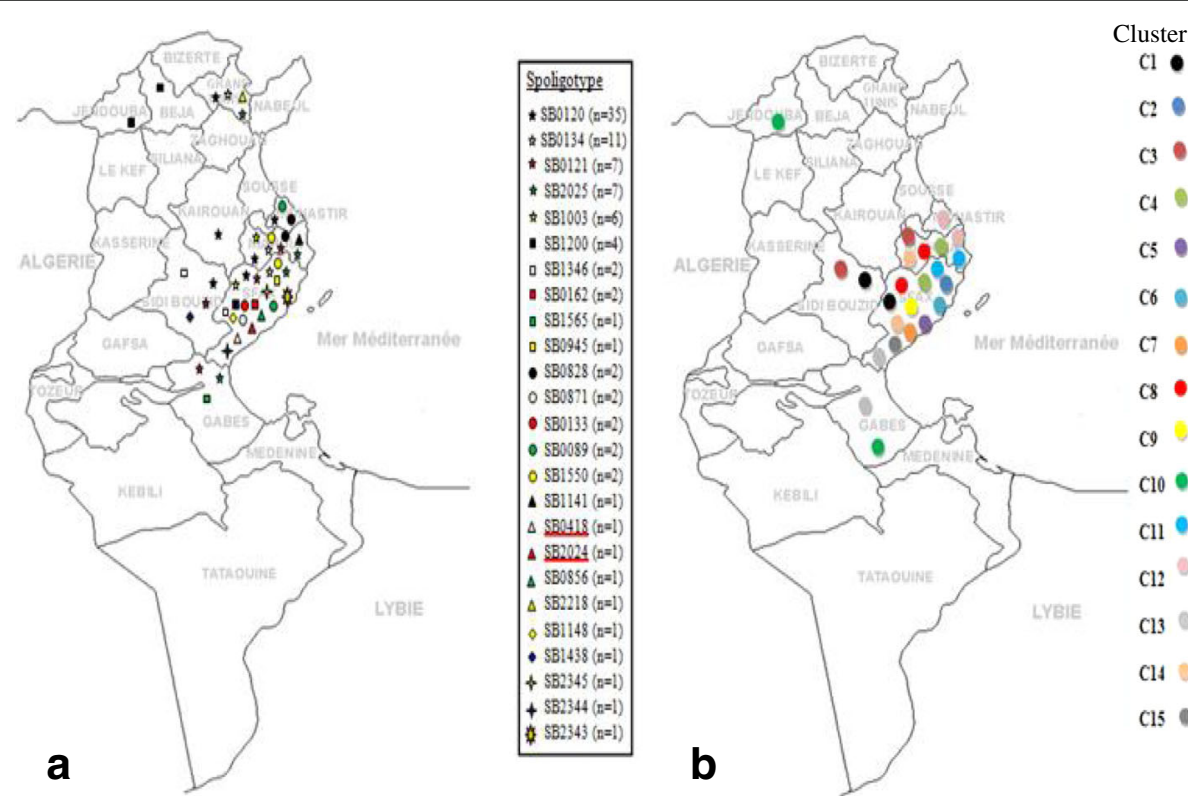

Fig. 1 Geographical distribution of clusters and spoligotypes. a Distribution of twenty five spoligotypes distributed on ten Tunisian regions. The two M.caprae spoligotypes are underlined with red color. b Distribution of fifteen clusters identified using the UPGMA algorithm 
1

Isolates

\section{Binary code}

$\mid \begin{array}{ll}103 & 110011110111111011111111111001111111110000\end{array}$

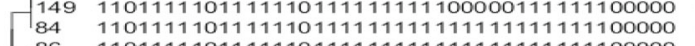
11011111011111101111111111111111111111000oo 1101111101111101111111111111111111111100000 1101111101111110111111111111111111111100000
110111110111111011111111111111111111100000 1101111101111110111111111111111111111100000 110111110111111011111111111111111111111100000 1100011101111110111111111111111111111100000 1101111101111010111111111111111111111100000 1101111101111111011111111111111111111111100000 110111110111111011111111111111111111100000 1101111101111110111111111111111111111100000 1101111001111110111111111111111111111100000 110111100111111011111111111111111111110000 1101111101111110111111111111111111111100000 110111110111111011111111111111111111100000 1101111101111110111111111111111111111100000
110111110111111011111111111111111111100000 1101111101111110111111111111111111111110000 110111110111110011111111111111111111111000000 110111110111111011110111111111111111110000 1101111101111110111111111110011111111100000 131 110111110111111011111111110011111111100000 $\mathrm{H}_{132}^{131} 11011111011111101111111111100011111111100000$ 11011111011111101111111111111111111111100000 1101111101111110111111111111111111111111100000 11011101011111101111111111110111111111100000 1100000101111110111111111111111111111110000 ooooooooooooooooooooooo011111111111111100000 oooooooooooooooooooooo001111111111111100000 1101111101111110111111111111111111111100000 110111110111111011111111111111111111110000 1101110101111110111111111110111111111100000 1101110101111110111111111110111111111100000 11011101011111101111111111110111111111100000

48

$-102 \quad 1101111101111110111111111111111111111100000$

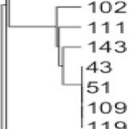
11111011111101111111111111111111111100000 1101111101111110111111111111111111111100000 11011111011111101111111111111111111111100000 1091101111101111110111111111111111111111100000 11011111011111101111111111111111111111100000 1101111101111110111111111111111111111100000 1101111101111110111111111111111111111100000 1101111101111110111111111101111111111100000 1101111101111110111111111111111111111100000 1100000101111110111111111111111111111100000 1100011101111110111111111111111111111100000 1100011101111110111111111111111111111100000
110001110111111011111111110000011111100000 1100011101111110111111111111111111111100000 1100011101111110111111111111111111111100000 1101111101111110111111111000111111111100000 1100011101111110111111011111111111111110000 11011111011111101111111111111111110111100000 1101111101111110111111111111111110111100000 1001111101111110111101111111111000111100000 1100011101111110111111111111111111111100000 1100011101111110111111111111111111111100000 1101111101111110111111111111111111111100000
110111110111111011111111111111111111100000 11000111011111100111111111111111111111100000 1101111100111110111111111111111111111100000 11011111011111101111011111111111111111100000 1101111101111110111101111111111111111100000 110001110111111011111101111101111111110000 1100011101111110111111011111011111111100000 1100011101111110111111011111011111111100000 1100011101111110111111011111011111111100000 1100011101111110111111011111011111111100000
1100011101111110111111011111011111111100000 $26 \quad 1100011101111110111111011111011111111100000$ 010000000000000011111111111101111111111100000 110001110111111011111011111111111111110000 1100011101111110111110111111111111111100000 1101111101111110111101111111111101111100000 1101111101111110111101111111111111111100000 1101111101111110111101111111111101111100000 01000000000000001111111111010100001111100000 1101111101111110111101111111111111111100000 1101111101111110111111111111111111111100000 110001110111111011111111111111111111111100000 1101111100111110111111111111111111111100000
ST

SB2345 SB0120 SB0120 SB0120 SB0120 SBO120 SB0134 SBO120 SBO120 SBO120 B0120 SB1550 SB0120 B0120 SB0120 SB0120 SB0856 SB1200 SB1200 SB1200 SB0120 SB1003 SB0133 SB0162 SB0162 SB0120 SB1003 B1003 SB1003 B0120 SB0120 SB0120 SB0120 SB0120 SB0120 SB0120 SB0120 SB1565 SB0120 SB0133 SB0120 SB0134
SB00134 (B.2344 SB0134 SB1148 SB0134 SB0134 SB0828 SB0828 SB2343 SB0134 SB0134 SB0120 SB0120 SB08871 SB0121 B0121 SB2025 SB2025 SB2025 SB2025 SB2025 SBO418 SB0089 SB0089 SBO121 SB1346 SB2024 SB0120 SB1141 SBO134

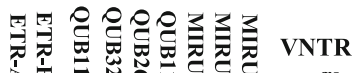
$>$ to 巡

55116552533 $\begin{array}{lllllllll}5 & 5 & 11 & 6 & 5 & 2 & 5 & 3 & 3 \\ 5 & 5 & 11 & 6 & 5 & 2 & 5 & 3 & 3\end{array}$ $\begin{array}{lllllllll}5 & 5 & 11 & 6 & 5 & 1 & 5 & 3 & 3 \\ 5 & 5 & 11 & 6 & 5 & 5 & 5 & 3 & 3\end{array}$ $\begin{array}{lllllllll}5 & 5 & 11 & 6 & 5 & 5 & 5 & 3 & 3\end{array}$ $\begin{array}{lllllllll}5 & 5 & 11 & 7 & 5 & 3 & 5 & 3 & 3\end{array}$ $\begin{array}{lllllllll}5 & 5 & 11 & 7 & 5 & 2 & 5 & 3 & 3 \\ 5 & 5 & 11 & 7 & 5 & 2 & 5 & 3 & 3\end{array}$ $\begin{array}{lllllllll}5 & 5 & 11 & 6 & 5 & 4 & 5 & 3 & 2 \\ 5 & 5 & 11 & 6 & 5 & 4 & 5 & 3 & 3\end{array}$ $\begin{array}{lllllllll}5 & 5 & 11 & 4 & 5 & 4 & 5 & 3 & 3\end{array}$ $\begin{array}{lllllllll}4 & 3 & 11 & 6 & 5 & 3 & 5 & 3 & 3 \\ 5 & 3 & 11 & 6 & 5 & 3 & 5 & 3 & 3\end{array}$ $\begin{array}{lllllllll}5 & 3 & 11 & 6 & 5 & 3 & 5 & 3 & 3 \\ 4 & 2 & 11 & 6 & 5 & 3 & 5 & 3 & 3\end{array}$ 4771166533533 $\begin{array}{lllllllll}5 & 5 & 11 & 6 & 5 & 3 & 5 & 3 & 3 \\ 5 & 5 & 11 & 6 & 5 & 5 & 3 & 3\end{array}$ $\begin{array}{lllllllll}4 & 5 & 11 & 6 & 5 & 3 & 5 & 3 & 3\end{array}$ $\begin{array}{lllllllll}4 & 5 & 11 & 6 & 5 & 3 & 5 & 3 & 3\end{array}$ $\begin{array}{lllllllll}4 & 5 & 11 & 6 & 5 & 3 & 5 & 3 & 3 \\ 4 & 5 & 11 & 5 & 5 & 5 & 5 & 3 & 3 \\ 4 & & 11 & 5 & 5 & 5\end{array}$ $\begin{array}{lllllllll}5 & 3 & 11 & 6 & 5 & 2 & 5 & 3 & 3 \\ 3 & 3 & 11 & 6 & 5 & 2 & 5 & 3 & 3\end{array}$ $\begin{array}{lllllllll}3 & 3 & 11 & 6 & 5 & 2 & 5 & 3 & 3 \\ 2 & 3 & 8 & 6 & 5 & 2 & 5 & 3 & 3\end{array}$ $\begin{array}{llllllll}5 & 610 & 7 & 5 & 2 & 5 & 3 & 3\end{array}$ 56611665225533 $\begin{array}{lllllllll}5 & 6 & 11 & 6 & 5 & 2 & 4 & 3 & 3 \\ 5\end{array}$ $\begin{array}{llllllll}5 & 11 & 4 & 4 & 4 & 5 & 3 & 3\end{array}$ $\begin{array}{lllllllll}5 & 5 & 11 & 5 & 4 & 3 & 5 & 3 & 3 \\ 5 & 4 & 11 & 6 & 3 & 1 & 5 & 3 & 3\end{array}$ $5 \begin{array}{lllllllll}5 & 11 & 6 & 2 & 4 & 5 & 3 & 3\end{array}$

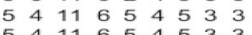
$\begin{array}{lllllllll}5 & 4 & 11 & 6 & 5 & 4 & 5 & 3 & 3 \\ 5 & 4 & 11 & 8 & 5 & 4 & 5 & 3 & 3\end{array}$ $\begin{array}{lllllllll}5 & 4 & 11 & 8 & 5 & 4 & 5 & 3 & 3 \\ 5 & 6 & 1 & 5 & 5 & 4 & 5 & 3 & 3\end{array}$ $\begin{array}{lllllllll}5 & 6 & 11 & 6 & 4 & 4 & 5 & 3 & 3 \\ 5 & 4 & 11 & 6 & 4 & 4 & 5 & 3 & 3\end{array}$ 541166445533 $\begin{array}{lllllllll}5 & 4 & 11 & 6 & 4 & 4 & 5 & 3 & 3 \\ 5 & 4 & 11 & 6 & 4 & 4 & 5 & 3 & 3\end{array}$ $\begin{array}{llllllllll}5 & 4 & 11 & 6 & 4 & 4 & 5 & 3 & 3 \\ 3 & 5 & 9 & 6 & 2 & 3 & 5 & 3 & 3\end{array}$ \begin{tabular}{lllllllll}
3 & 5 & 11 & 6 & 2 & 3 & 6 & 3 & 3 \\
\hline & 5 & 11 & 6 & 2 & 2 & 5 & 3 & 3
\end{tabular} $\begin{array}{lllllllll}3 & 5 & 11 & 6 & 2 & 3 & 5 & 3 & 3\end{array}$ $\begin{array}{lllllllll}3 & 5 & 11 & 6 & 2 & 3 & 5 & 3 & 3\end{array}$ $\begin{array}{lllllllll}3 & 5 & 11 & 6 & 2 & 3 & 5 & 3 & 3 \\ 3 & 5 & 1 & 6 & 2 & 5 & 5 & 3 & 3\end{array}$ $\begin{array}{lllllllll}4 & 5 & 11 & 6 & 1 & 4 & 5 & 3 & 3\end{array}$ $\begin{array}{lllllllll}4 & 5 & 11 & 6 & 5 & 4 & 4 & 3 & 4 \\ 5 & 5 & 10 & 6 & 2 & 4 & 5 & 4 & 3\end{array}$ $5 \quad 51062245443$ $\begin{array}{lllllllll}5 & 7 & 10 & 6 & 2 & 4 & 5 & 4 & 3 \\ 5 & 5 & 11 & 6 & 2 & 4 & 5 & 4 & 3\end{array}$ 55116444543 $\begin{array}{lllllllll}5 & 4 & 11 & 3 & 5 & 4 & 5 & 4 & 3 \\ 5 & 4 & 11 & 3 & 5 & 4 & 5 & 4 & 3\end{array}$ $\begin{array}{lllllllll}5 & 4 & 11 & 5 & 5 & 4 & 5 & 4 & 3\end{array}$ $\begin{array}{llllllll}2 & 11 & 3 & 5 & 5 & 4 & 3\end{array}$ $\begin{array}{lllllllll}5 & 4 & 11 & 6 & 5 & 4 & 5 & 4 & 3 \\ 5 & 5 & 11 & 7 & 5 & 6 & 5 & 4 & 3\end{array}$ $\begin{array}{lllllllll}5 & 3 & 11 & 6 & 5 & 1 & 5 & 4 & 3\end{array}$ $\begin{array}{lllllllll}5 & 4 & 11 & 6 & 5 & 2 & 5 & 4 & 3 \\ 5 & 5 & 11 & 6 & 5 & 2 & 5 & 4 & 3\end{array}$ $\begin{array}{lllllllll}5 & 5 & 11 & 6 & 5 & 2 & 5 & 4 & 3\end{array}$

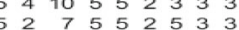

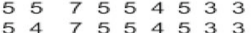
\begin{tabular}{lllllllll}
5 & 4 & 7 & 5 & 5 & 4 & 5 & 3 & 3 \\
4 & 5 & 11 & 9 & 5 & 3 & 5 & 4 & 3 \\
\hline & 6 & 1 & 9 & 5 & 3 & 5 & 4 & 3
\end{tabular} $\begin{array}{lllllllll}4 & 5 & 11 & 9 & 5 & 3 & 5 & 4 & 3 \\ 7 & 6 & 11 & 9 & 5 & 3 & 5 & 4 & 3\end{array}$ 64843335533 $\begin{array}{lllllllll}6 & 5 & 11 & 4 & 4 & 2 & 2 & 3 & 3 \\ 6 & 4 & 10 & 7 & 5 & 2 & 5 & 3 & 3\end{array}$ 641074445533 66106442533 651066445533 6510642533 $\begin{array}{lllllllll}6 & 5 & 10 & 6 & 4 & 2 & 5 & 3 & 3 \\ 6 & 5 & 10 & 6 & 4 & 2 & 5 & 3 & 3\end{array}$ $\begin{array}{lllllllll}6 & 5 & 10 & 6 & 4 & 2 & 5 & 3 & 3 \\ 5 & 1 & 11 & 10 & 3 & 4 & 5 & 2 & 3\end{array}$ 331185566433 $\begin{array}{lllllllll}3 & 3 & 11 & 8 & 5 & 4 & 4 & 3 & 3 \\ 2 & 3 & 11 & 7 & 5 & 2 & 5 & 3 & 2 \\ 4 & 3 & 11 & 7 & 5 & 2 & 3 & 3 & 2\end{array}$ $\begin{array}{lllllllll}2 & 3 & 11 & 7 & 5 & 2 & 5 & 3 & 2 \\ 4 & 3 & 11 & 7 & 5 & 2 & 3 & 3 & 2\end{array}$ $\begin{array}{lllllllll}4 & 3 & 11 & 7 & 5 & 2 & 5 & 3 & 2\end{array}$ $\begin{array}{llllllllll}5 & 3 & 6 & 9 & 2 & 4 & 5 & 4 & 9 \\ 8 & 4 & 9 & 7 & 2 & 1 & 2 & 3 & 3\end{array}$ 4211165535533 $\begin{array}{lllllllll}9 & 4 & 10 & 7 & 2 & 1 & 2 & 3 & 3\end{array}$ $\begin{array}{llllllllll}3 & 2 & 7 & 5 & 5 & 4 & 5 & 2 & 4 \\ 6 & 2 & 6 & 3 & 4 & 3 & 2 & 4 & 3\end{array}$

P1 Sfax P1 Sidibouzid C1 P1 Sfax P3 Sfax P4 Mahdia $\begin{array}{ll}\text { P5 } & \text { Sfax } \\ \text { P5 } & \text { Sfax }\end{array}$ P6 Kairouan P8 Manoub P9 Sfax P10 Sfax P11 Mahdia C3

P12 Sfax

P13 Mahdia

P14 Sfax

P14 Sfax

P14 Sfax

P16 Mahdia

P17 Sfax

P19 Jendoub

\begin{tabular}{ll} 
P2O & Beja \\
P21 & Sfax \\
\hline
\end{tabular}

P21 Sfax

P22 Sidi bouzid

P23 Sfax

P25 Sfax

P26 5 Sfax

P27 Manouba

\begin{tabular}{ll} 
P28 & Sfax \\
P29 & Sfax \\
\hline
\end{tabular}

P30 Sfax

P30 Sfax

P30 Mahdi

P31 Monastir

P32 Sfax

P34 Sfax

P34 Sfax

P34 Sfax

P35 Sfax

P37 Sfax

P37 Gabes

P38 Sfax

P40 Sidi

P41 Sfax

P41 Mahdi

P42 Sfax

P44 Mahdia

P45 Sfax

P47 Sfax

P48 Mahdia $\mathrm{C} 12$

P49 Sfax

P50 Sfax

P52 Mahdia

P53 Sfax

P55 Sfax

P56 Sfax
P57

P58 Sidi bouzid

P59 Gabes

P59 Gabe

P60 Manouba

P61 Sfax

P61 Sfax

$\begin{array}{ll}\text { P61 } & \text { Sfax } \\ \text { P62 } & \text { Sfax }\end{array}$

P63 Monastir

P64 Sfax

P65 Sidi bouzid

$\begin{array}{ll}\text { P66 } & \text { Sfax } \\ \text { P67 Sfax } & \end{array}$

P67 Sfax

P68 Sfax

P70 Sidi bouzid 
(See figure on previous page.)

Fig. 2 Dendogram of cluster analysis. Dendrogram generated with the UPGMA (unweighted pair group method with arithmetic average) and Neighbour Joining (NJ) clustering methods using the MIRU-VNTR data using Tree graph 2 software showing the genetic relationships of the 96 Mycobacterium bovis isolates. A group of two or more isolates sharing the same MIRU-VNTR pattern is defined as a cluster. ST: Spoligotype as defined in the M. bovis Spoligotype Database website (http://www.mbovis.org). * Isolate corresponding to M. caprae

loci with higher diversity were QUB-11b, ETR-B, ETRA, QUB-3232, QUB26 and QUB-11a with a discriminatory power $h$ corresponding to $0.727,0.724,0.650$, $0.583,0.577$, and 0.445 , respectively. The MIRU 31, MIRU26 and MIRU 4 loci displayed a very little allelic diversity $(0.370,0.249$, and 0.158 , respectively).

Our results showed a large genotypic variety observed within the main spoligotypes which was split into several MIRU-VNTR types as previously shown in Tunisia and in France [3, 11]. MIRU-VNTR typing results for 6 common loci (ETR A, ETR B, MIRU4 (ETRD), QUB11a, QUB11b and QUB3232) were available for strains from Tunisia and France showing shared genotypes (Additional file 1).

MIRU-VNTR analysis showed a large genotypic variety observed within the main spoligotype that was split into several MIRU-VNTR types: 29 in SB0120 ( $h=0.983), 10$ in SB0134 $(h=0.981)$ and 7 in SB0121 $(h=1)$. Genotyping revealed a pattern common for different geographic regions (P11, P13, P30, P41, P48, P59 and P61) (Fig. 1, Fig. 2). Our results showed that Sfax, located in southern Tunisia, represents a highrisk area with a high level of genetic diversity with 20 and 63 out of the 25 and the 73 detected spoligotypes and genotypes, respectively.

Fifteen clusters including 36 isolates (37.5\%) were identified using the UPGMA algorithm and the largest three clusters (C1, C10 and C15) had four isolates; while most clusters had only two (Fig. 2). The most common VNTR profiles P30, P34 and P61 were found in four isolates each. Moreover, most clusters showed the same spoligotyping pattern for all isolates. Isolates with the spoligotyping patterns SB1438, SB2345, and SB0120 presented a similar MIRU-VNTR profile (P1: 5.5.11.6.5.2.5.3.3). It also occurred in the case of isolates with spoligotypes SB0120 and SB1565 where MIRUVNTR profiles were P37: 5.5.10.6.2.4.5.4.3, and in isolates with spoligotypes SB1346 and SB0121 (MIRUVNTR profile P67: 4.3.11.7.5.2.5.3.2) (Fig. 2). When both typing techniques were combined, the level of discrimination was 0.993 and 78 different spoligo-MIRU-VNTR types were observed.

For SB0120, the main MIRU-VNTR pattern (MV16), 5.5.3.11.4.6 identified in our study was detected in the Central East of France in the Côte d'Or region. Additionally, pattern MV6 (5.5.3.11.4.4) was identified for strains with SB0120 from France and Tunisia. Interestingly, four genotypes (MV21, MV10, MV53 and MV63) detected in our strains with an SB0120 spoligotype pattern from Sfax were previously described by LamineKhmiri et al. in the same region [3] but not detected in strains from France [11] (Table 1, Additional file 1). Moreover, MIRU-VNTR genotype MV53 (6.5.3.10.2.6) was detected according to our study in strains corresponding to the spoligotype SB2025; which highlights matching results only with the study conducted by Lamine-Khmiri et al. [3] (Table 1, Additional file 1). Interestingly, the pattern MV36 (5.4.3.11.4.6) was obtained in strains with spoligotype pattern SB0134 from Tunisia and France.

\section{Discussion}

Our study represented a large analysis including 96 characterized M. bovis out of 149 slaughtered cattle from ten Tunisian regions showing TB compatible lesions in the lymph nodes after routine inspection. However, two Tunisian studies have previously reported data about bTB in Tunisia analyzing only 35 and $6 \mathrm{M}$. bovis isolates out of 100 cattle and 306 milk samples, respectively [3, 5]. The allelic diversity of spoligotype patterns among the $M$. bovis strains isolated in our study $(h=0.842)$ were relatively more than the ones previously found by Lamine-Khemiri et al. and Kahla et al. (0.733 and 0.753, respectively) in Tunisia $[3,5]$. This fact could be mainly due to the differences in the number of isolates.

Of the 25 detected $M$. bovis spoligotype patterns, 8 patterns, accounting for $75 \%$ of all the isolated strains, have previously been detected in strains isolated from

Table 1 Shared MIRU-VNTR genotypes of strains with spoligotype pattern SB0120 from Tunisia and France

\begin{tabular}{|c|c|c|c|}
\hline & Tunisia & & France \\
\hline VNTR type & This study & Lamine-Khemiri et al. [3] & Hauer et al. [11] \\
\hline MV6 & $5.5 .3 .11 .4 .4^{£}$ & $5.5 .3 .11 .4 .4^{£}$ & $5.5 .3 .11 .4 .4^{£}$ \\
\hline MV16 & $5.5 .3 .11 .4 .6^{€}$ & & $5.5 .3 .11 .4 .6^{€}$ \\
\hline MV21 & $5.5 .3 .11 .2 .6^{7}$ & $5.5 .3 .11 .2 .6^{¥}$ & \\
\hline MV10 & $3.5 .3 .11 .3 .6^{¥}$ & $3.5 \cdot 3.11 .3 .6^{¥}$ & \\
\hline MV53 & $6 \cdot 5 \cdot 3 \cdot 10.2 .6^{¥}$ & $6 \cdot 5 \cdot 3 \cdot 10.2 .6^{¥}$ & \\
\hline MV63 & 5.6.3.11.2.6 & 5.6.3.11.2.6 & \\
\hline
\end{tabular}

Results from Tunisia and France have previously been published. [3, 11] Additional file 1 shows more details concerning the comparison of our results to those of two previous studies. £Matching patterns of strains from the two Tunisian studies and France. $€$ Matching patterns of strains from our study and France. $¥$ Matching patterns of strains from our study and Lamine-Khemiri et al. MV53 genotype was also detected in strains with SB2025 genotype in our study and in Tunisia previously published by Lamine-Khemiri et al 
Tunisia [3]. The frequency of three common spoligotypes most detected in our strains (SB0120, SB0121, SB0134) are quite similar to those detected in Tunisia by LamineKhemiri et al. [3], in Algeria by Sahraoui et al. [20] are also in France by Hauer et al. [11]. They were also found in other European countries as Italy, Spain and Portugal [10, 21, 22]. Our present results corroborate previous studies showing a more frequent occurrence of $M$. bovis strains of spoligotype pattern SB0120 causing bTB in Tunisia (36-37\%), in Algeria (39\%) [20] and in France since 1978 accounting for $26 \%$ as mentioned by Hauer et al. [11]. Interestingly, the spoligotype SB0134 was identified as the second predominant type in Tunisia, the second most frequently isolated type in France [11] and was highly prevalent in cattle from neighbouring Algeria [20]. SB0121, the third most abundant spoligotype in our study (7.2\%), is also present in France (6\%) [11], and more frequently found in Algeria (21\%) [20].

The comparative study of the Tunisian and French spoligotypes and MIRU-VNTR profiles could further support the French input to the Tunisian $M$. bovis population considering the striking similarity. There have been very strong historical commercial links between Tunisia and France starting during the French colonial period. The importation of French cattle could explain the majority of our genotypic results and the similarity with the $M$. bovis French population genotypes is concerned. The Food and Agriculture Organization in Tunisia, states documentation concerning the imported breeds in Tunisia originated from North America and Europe only from 1986 to 1989 [23]. Therefore the increased effort to control bTB in Europe or North America had already allowed almost eradication of the disease [24]. Thus, introduction of $M$. bovis from Europe into African countries has previously been suggested [10, 25]. In addition, Sahraoui et al. [20] mentioned that some strains of $M$. bovis found in Algeria may have been independently introduced from France (or more generally continental Europe). In fact, in Tunisia, the introduction of cattle from neighboring countries such Algeria and Lybia via non controlled routes is continuing up to date; which is considered one of the main sources of the maintenance of the infection in Tunisian cattle due to the absence of control and eradication campaigns. In addition, there are exclusive Tunisian spoligotypes clearly derived from strains SB0120, SB0134 or SB0121; some of which have already been described $[11,20]$, suggesting that the imported strains mutated in Tunisia. On the other hand, M. bovis mutates rather slowly; it is then highly possible that these mutated strains have long existed in the territory and that possibly spillback to the breed animals was introduced in the country.
The origin farms of the animals could not be traced since samples were taken only from cattle belonged to the private unorganized livestock characterized by a multiple selling of the animals prior to slaughter. However, the majority of animals could be dairy cattle; thus it is very improbable that animals had come from the same herds. Thus, our study demonstrates the importance of the elaboration of a tracing system which could be a useful tool for bTB monitoring.

Our findings emphasize previous claims that cattle could be infected by $M$. caprae spoligotypes (SB0418, SB2024) $[3,6]$. Interestingly, the SB2024 profile has recently been described in Tunisia [3] whereas the spoligotype SB0418 has been mentioned in Central and Eastern European countries $[10,26,27]$ as the most frequent spoligotype found in human and animal isolates [3, 27]. The current study raises the issue of a cross contamination in and between cattle and goats during their breeding or importation. In Tunisia, the herd of goats was estimated at 1.5 million head. In the North, goats are reared in extensive mixed farming systems with sheep and cows. Meanwhile, almost $60 \%$ of the goats are located in the Center and South of Tunisia, reared in semi-intensive oasis systems, in small herds [28]. However, to our knowledge, no data is available about the importation of small ruminants in the country although the introduction of $M$. caprae infected cattle and/or goats from other countries could be possible.

The spatial distribution of the M. bovis strains reveals the existence of isolates with shared spoligotypes and MIRU-VNTR profiles between different geographic Tunisian regions: Sfax and Gabes (P59), Sfax and Mahdia (P13, P30, P4 and P61), Mahdia and Monastir (P48), and Mahdia and Sidi Bouzid (P11), which revealed the movement of animals between them. This exchange event is probably related to economic facts like the trade of infected animals and the geographical distribution in the area. In fact, Sfax, Gabes, Mahdia, Sidi bouzid, and Monastir regions are contiguous states which may facilitate the movement of cattle among them.

Isolates corresponding to the cluster C1 (SB0120, SB1438 and SB2345 spoligotypes), showed the same MIRU-VNTR allelic profile, and SB1438 and SB2345 could be probably derived from a SB0120 isolate. In a similar way, isolates corresponding to clusters $\mathrm{C} 10$ and C15 have identical MIRU-VNTR allelic profiles, and the loss of a single spacer could be compatible with a onestep evolution $(\mathrm{SB} 0120 \rightarrow$ SB1565; SB0121 $\rightarrow$ SB1346, respectively) asmentioned by Romero et al. [29]. It has also been hypothesized that the appearance of new strains diverged from pre-existing clones which have lost spacers [29-32]. However, the molecular techniques used in our study cannot determine the oldest strains. Thus, further analysis by whole genome sequencing would be interesting for this purpose. 


\section{Conclusions}

The molecular data obtained until now would greatly support and provide hints to improve the national eradication campaign since it helps to determine the origin of outbreaks and better understand the link in-between btB transmission. Further laboratory testing, periodic sampling from different slaughterhouses and additional herd epidemiological studies should be conducted to determine the exact bTB prevalence and to further understand the mode of transmission.

\section{Additional file}

Additional file 1: Molecular typing data comparison of $M$. bovis isolates in different regions in Tunisia and in France. The data provided shows common spoligotypes prevalence and MIRU-VNTR typing results for 6 common loci (ETR A, ETR B, MIRU4 (ETRD) for strains isolated from Tunisian and French regions. (PDF $114 \mathrm{~kb}$ )

\section{Acknowledgments}

This work is part of a doctoral thesis by Saif Eddine Djemal.

This work was supported by the research program of the Ministry of Higher Education and Scientific Research, Tunisia.

We would like to acknowledge Wissem Gdoura for his assistance with laboratory testing of specimens and also Mohamed Ghariani and Lilia Chaker for coordinating this study at the Regional Hygiene Care Mycobacteriology Laboratory, Hedi-Chaker University Hospital, Sfax, Tunisia. We thank the VISAVET Centre in Spain for the training course in molecular techniques, specially J. Gimeno and F. Lozano.

This work was supported by the Programa de Tecnologías Avanzadas en Vigilancia Sanitaria (TAVS) from the Comunidad de Madrid (ref. S2013/ABI-2747) The authors are eventually grateful to Kamel MAALOUL, translator and English professor for having proofread the manuscript.

\section{Funding}

No specific funding for this work.

\section{Availability of data and materials}

All data generated or analysed during this study are included in this published article.

\section{Authors' contributions}

SD conception and design of the study, sampling of animals, culturing of Mycobacteria, molecular typing, VNTR typing, writing of the manuscript. MS conception and design of the study, writing and review of the manuscript. SS conception and design of the study, participated in the manipulation for the isolation of strains of Mycobacterium and for molecular gene characterization, interpreted the results and revised critically the manuscript. SK and CM Data curation. JB contribution in paper writing and review. FM-A Participated in the study design, interpretation of results and revised critically the manuscript. BR principal supervision and support for molecular typing, VNTR typing at Centro de Vigilancia Sanitaria Veterinaria (VISAVET), Madrid, Spain writing of the manuscript. RG Supervised the experimental work, interpretation of results and revised critically the manuscript. All authors read and approved the final manuscript.

Ethics approval and consent to participate

Not applicable

\section{Consent for publication}

Not applicable

Competing interests

The authors declare that they have no competing interests.

\section{Publisher's Note}

Springer Nature remains neutral with regard to jurisdictional claims in published maps and institutional affiliations.

\section{Author details}

${ }^{1}$ Department of Life Sciences, Research Laboratory of Environmental Toxicology-Microbiology and Health (LR17ES06), Faculty of Sciences, University of Sfax-Tunisia, Sfax, Tunisia. ${ }^{2}$ Department of Biology, Preparatory Institute for Engineering Studies, University of Sfax-Tunisia, Sfax, Tunisia. ${ }^{3}$ Department of Microbiology, Regional Hygiene Care Mycobacteriology Laboratory, Hedi-Chaker University Hospital, Sfax, Tunisia. ${ }^{4}$ Department of Biology, Faculty of Pharmacy, University of Monastir-Tunisia, Monastir, Tunisia. ${ }^{5}$ Department of Microbiology, National Reference Laboratory of Mycobacteria, Research Unit (UR12SP18), A, Mami University Hospital of Pneumology, Ariana, Tunisia. ${ }^{6}$ MAEVA SERVET SL. C/ de la Fragua 3, 28749, Alameda del Valle, Madrid, Spain. ${ }^{7}$ Centro de Vigilancia Sanitaria Veterinaria (VISAVET), Universidad Complutense, Avda. Puerta de Hierro s/n, 28040 Madrid, Spain

Received: 26 May 2017 Accepted: 6 December 2017

Published online: 16 December 2017

\section{References}

1. Olea-Popelka F, Muwonge A, Perera A, Dean AS, Mumford E, Erlacher-Vindel $E$, et al. Zoonotic tuberculosis in human beings caused by Mycobacterium Bovis - a call for action. Lancet Infect Dis. 2017:17:e21-5.

2. Cosivi O, Grange JM, Daborn CJ, Raviglione MC, Fujikura T, Cousins D, et al. Zoonotic tuberculosis due to Mycobacterium Bovis in developing countries. Emerg Infect Dis. 1998:4:59-70.

3. Lamine-Khemiri H, Martínez R, García-Jiménez WL, Benítez-Medina JM, Cortés M, Hurtado I, et al. Genotypic characterization by spoligotyping and VNTR typing of Mycobacterium Bovis and Mycobacterium Caprae isolates from cattle of Tunisia. Trop Anim Health Prod. 2014:46:305-11.

4. Corner LA, Gormley E, Pfeiffer DU. Primary isolation of Mycobacterium Bovis from bovine tissues: conditions for maximising the number of positive cultures. Vet Microbiol. 2012;156:162-71.

5. Kahla IB, Boschiroli ML, Souissi F, Cherif N, Benzarti M, Boukadida J, et al. Isolation and molecular characterisation of Mycobacterium Bovis from raw milk in Tunisia. Afr Health Sci. 2011:11:2-5.

6. Müller B, Steiner B, Bonfoh B, Fané A, Smith NH, Zinsstag J. Molecular characterisation of Mycobacterium Bovis isolated from cattle slaughtered at the Bamako abattoir in Mali. BMC Vet Res. 2008:4:26.

7. Ghariani A, Jaouadi T, Smaoui S, Mehiri E, Marouane C, Kammoun S, et al. Diagnosis of lymph node tuberculosis using the GeneXpert MTB/RIF in Tunisia. Int J Mycobacteriology. 2015;4:270-5.

8. Siala M, Smaoui S, Taktak W, Hachicha S, Ghorbel A, Marouane C, et al. Firsttime detection and identification of the mycobacterium tuberculosis complex members in extrapulmonary tuberculosis clinical samples in south Tunisia by a single tube tetraplex real-time PCR assay. Pluschke G, editor. PLoS Negl Trop Dis. 2017;11:e0005572.

9. Frothingham R, Meeker-O'Connell WA. Genetic diversity in the mycobacterium tuberculosis complex based on variable numbers of tandem DNA repeats. Microbiology. 1998;144:1189-96.

10. Haddad N, Ostyn A, Karoui C, Masselot M, Thorel MF, Hughes SL, et al. Spoligotype diversity of Mycobacterium Bovis strains isolated in France from 1979 to 2000. J Clin Microbiol. 2001;39:3623-32.

11. Hauer A, De Cruz K, Cochard T, Godreuil S, Karoui C, Henault S, et al. Genetic evolution of Mycobacterium Bovis causing tuberculosis in livestock and wildlife in France since 1978. PLoS One. 2015:10:e0117103.

12. Eisenach KD, Cave MD, Bates JH, Crawford JT. Polymerase chain reaction amplification of a repetitive DNA sequence specific for mycobacterium tuberculosis. J Infect Dis. 1990;161:977-81.

13. Kamerbeek J, Schouls LEO, Kolk A, Van Agterveld M, Van Soolingen D, Kuijper $\mathrm{S}$, et al. Simultaneous detection and strain differentiation of mycobacterium tuberculosis for diagnosis and epidemiology. J Clin Microbiol. 1997:35:907-14

14. Smith NH, Upton P. Naming spoligotype patterns for the RD9-deleted lineage of the mycobacterium tuberculosis complex; www.Mbovis.org. Infect Genet Evol J Mol Epidemiol Evol Genet Infect Dis. 2012;12:873-6.

15. Roring S, Scott A, Brittain D, Walker I, Hewinson G, Neill S, et al. Development of variable-number tandem repeat typing of Mycobacterium 
Bovis: comparison of results with those obtained by using existing exact tandem repeats and Spoligotyping. J Clin Microbiol. 2002;40:2126-33.

16. Supply P, Mazars E, Lesjean S, Vincent V, Gicquel B, Locht C. Variable human minisatellite-like regions in the mycobacterium tuberculosis genome. Mol Microbiol. 2000;36:762-71.

17. Allix C, Walravens K, Saegerman C, Godfroid J, Supply P, Fauville-Dufaux M. Evaluation of the epidemiological relevance of variable-number tandemrepeat genotyping of Mycobacterium Bovis and comparison of the method with IS6110 restriction fragment length polymorphism analysis and Spoligotyping. J Clin Microbiol. 2006;44:1951-62.

18. Skuce RA, McCorry TP, McCarroll JF, Roring SM, Scott AN, Brittain D, et al. Discrimination of mycobacterium tuberculosis complex bacteria using novel VNTR-PCR targets. Microbiology. 2002;148:519-28.

19. Hunter PR, Gaston MA. Numerical index of the discriminatory ability of typing systems: an application of Simpson's index of diversity. J Clin Microbiol. 1988:26:2465-6.

20. Sahraoui N, Müller B, Guetarni D, Boulahbal F, Yala D, Ouzrout R, et al. Molecular characterization of Mycobacterium Bovis strains isolated from cattle slaughtered at two abattoirs in Algeria. BMC Vet Res. 2009;5:4.

21. Duarte EL, Domingos M, Amado A, Botelho A. Spoligotype diversity of Mycobacterium Bovis and Mycobacterium Caprae animal isolates. Vet Microbiol. 2008:130:415-21.

22. Rodríguez S, Romero B, Bezos J, de Juan L, Alvarez J, Castellanos E, et al. High spoligotype diversity within a Mycobacterium Bovis population: clues to understanding the demography of the pathogen in Europe. Vet Microbiol. 2010;141:89-95.

23. FAO. Tunisie : Rapport National sur les Ressources Génétiques animales [Internet]. 2001 [cited 2017 May 16]. Available from: http://ftp.fao.org/ docrep/fao/010/a1250e/annexes/CountryReports/Tunisia.pdf

24. Caffrey JP. Status of bovine tuberculosis eradication programmes in Europe. Vet Microbiol. 1994;40:1-4.

25. Njanpop-Lafourcade BM, Inwald J, Ostyn A, Durand B, Hughes S, Thorel M-F, et al. Molecular typing of Mycobacterium Bovis isolates from Cameroon. J Clin Microbiol. 2001;39:222-7.

26. Prodinger WM, Eigentler A, Allerberger F, Schönbauer M, Glawischnig W. Infection of red deer, cattle, and humans with Mycobacterium Bovis subsp. caprae in western Austria. J Clin Microbiol. 2002:40:2270-2

27. Erler W, Martin G, Sachse K, Naumann L, Kahlau D, Beer J, et al. Molecular fingerprinting of Mycobacterium Bovis subsp. caprae isolates from central Europe. J Clin Microbiol. 2004;42:2234-8.

28. Ammar H, Boda R, Ben Younes M, López S. Goat breeding systems in the South of Tunisia (Tataouine). Options Méditerranéennes Econ. Soc. Environ. Sustain. Sheep Goat Prod Syst A. 2011. p. 283-88.

29. Romero B, Aranaz A, Sandoval Á, Álvarez J, de Juan L, Bezos J, et al. Persistence and molecular evolution of Mycobacterium Bovis population from cattle and wildlife in Doñana National Park revealed by genotype variation. Vet Microbiol. 2008;132:87-95.

30. Van Embden JDA, Van Gorkom T, Kremer K, Jansen R, Van der Zeijst BAM Schouls LM. Genetic variation and evolutionary origin of the direct repeat locus of mycobacterium tuberculosis complex bacteria. J Bacteriol. 2000;182:2393-401.

31. Smith NH, Dale J, Inwald J, Palmer S, Gordon SV, Hewinson RG, et al. The population structure of Mycobacterium Bovis in great Britain: clonal expansion. Proc Natl Acad Sci U S A. 2003;100:15271-5.

32. Aranaz A, Romero B, Montero N, Álvarez J, Bezos J, de Juan L, et al. Spoligotyping profile change caused by deletion of a direct variable repeat in a mycobacterium tuberculosis Isogenic laboratory strain. J Clin Microbiol. 2004:42:5388-91.

\section{Submit your next manuscript to BioMed Central and we will help you at every step:}

- We accept pre-submission inquiries

- Our selector tool helps you to find the most relevant journal

- We provide round the clock customer support

- Convenient online submission

- Thorough peer review

- Inclusion in PubMed and all major indexing services

- Maximum visibility for your research

Submit your manuscript at www.biomedcentral.com/submit

) Biomed Central 